\title{
COMPORTAMENTO EM CORROSÃO DE JUNTAS SOLDADAS DE AÇOS INOXIDÁVEIS EM MEIOS CONTENDO ÍONS CLORETOS
}

\section{Resumo}

David Hebert Vieira 1

Daniel Fraga Pinto 2

José Antônio Nunes de Carvalho 3

Paulo Sérgio de SairreBálsamo 4

Leonardo Barbosa Godefroid 5

Luiz Cláudio Cândido 5

Avaliou-se a suscetibilidade de aços inoxidáveis ferríticos soldados com aços inoxidáveis austeníticos quanto ao fenômeno de trincamento por corrosão sob tensão (TCST), em soluções aquosas contendo $3,5 \%$ (peso) $\mathrm{NaCl}$, e $42 \%$ (peso) $\mathrm{MgCl}_{2}$. As técnicas empregadas para ensaios de TCST foram: carga constante e deformação constante no eletrodo. Empregaram-se metodologias da mecânica de fratura, onde se utilizaram CPs do tipo tração-compacto, C(T). Foi verificado que os materiais em estudo foram suscetíveis a TCST em solução aquosa contendo $42 \% \mathrm{MgCl}_{2}$, na temperatura de ebulição. Notou-se que o trincamento por CST ocorre a partir da pré-trinca, na zona austenítica, e prossegue para a região ferrítica. Análises microfractográficas indicaram que tanto na região da fratura por TCST quanto na zona de arrancamento final por tração a fratura foi frágil.

Palavras-chave: Aços inoxidáveis; Juntas soldadas; Corrosão sob tensão.

\section{CORROSION BEHAVIOR OF STAINLESS STEELS WELDS IN CHLORIDE SOLUTIONS}

\begin{abstract}
\section{INTRODUÇÃo}

Dentro da engenharia de materiais, destaca-se o desenvolvimento de técnicas e consumíveis para soldagem de aços inoxidáveis ferríticos com aços inoxidáveis austeníticos, objetivando aliar a elevada resistência à corrosão sob tensão, e boa condutividade térmica dos aços inoxidáveis ferríticos à boa soldabilidade apresentada pelos aços inoxidáveis austeníticos.

Nos últimos anos, os aços inoxidáveis têm recebido considerável atenção por uma série de razões tais como: elevada resistência à corrosão e razões econômicas, ou seja, substituição de ligas caras por alternativas mais baratas e de maior vida
\end{abstract}

The behavior in stress corrosion cracking (SCC) of ferritic stainless steels welded with austenitic stainless steels was evaluated in aqueous solutions containing 3.5 (weight\%) $\mathrm{NaCl}$, and 42 (weight\%) $\mathrm{MgCl}_{2}$ have been employed. The experiments included constant load and constant deformation of the electrode. Metodology of mechanical fracture was applied where precracked compact type - $\mathrm{C}(\mathrm{T}) \mathrm{s}$ - specimens have been used. Their fractographic aspects after SCC were analyzed. It was verified that the materials in study were SCC susceptible in aqueous solution containing 42 weight\% $\mathrm{MgCl}_{2}$. It was noticed that the cracks start from the precrack in the austenitic area and it continues inside the ferritic area. Key words: Stainless steels; Welding; Stress corrosion cracking.

útil, elevada resistência à corrosão e boas propriedades mecânicas.

O fenômeno de trincamento por corrosão sob tensão (TCST) ocorre quando um material suscetível (geralmente ligas passiváveis) é submetido a tensões trativas, aplicadas ou residuais e, simultaneamente, a um meio corrosivo específico.(1-4) Os ensaios de TCST em juntas soldadas com aplicação de técnicas de mecânica de fratura como ferramenta são métodos comumente usados para avaliar o comportamento de materiais em diferentes meios. (5)

Pesquisas estão sendo feitas no sentido de se entender melhor o comportamento da junta soldada em aços inoxidáveis, particularmente em aços ferríticos soldados com metal de adição de aços austeníticos, em meios agressivos submetidos a esforços externos e, desta forma, viabilizar o desenvolvimento de técnicas e consumíveis para soldagem de aços inoxidáveis nestas condições.

\footnotetext{
${ }^{1}$ Engo Metalurgista - Escola de Minas/UFOP-Gerdau/Divinópolis-MG

2 Engo Metal.; M.Sc.; Membro da ABM, danielfp10@yahoo.com.br

3 Eng ${ }^{\circ}$ Metal.; M.Sc.; ACESITA S.A., jancarvalho@acesita.com.br

4 Engo Mecânico.; M.Sc.; D.Sc; ACESITA S.A., pbalsamo@acesita.com.br

${ }^{5}$ Eng ${ }^{\circ}$ Metal.; M.Sc.; D.Sc; Membro da ABM, Prof. Adjunto; Grupo de Estudos sobre Fratura de Materiais; Dep. Eng. Metalúrgica e de Materiais - Escola de Minas/UFOP, candido@em.ufop.br, leonardo@demet.em.ufop.br
} 
Tabela 1. Composição química dos materiais (\% peso).

\begin{tabular}{cccccccccc}
\hline $\mathbf{A I S I}$ & $\mathbf{C}$ & $\mathbf{M n}$ & $\mathbf{S i}$ & $\mathbf{P}$ & $\mathbf{S}$ & $\mathbf{C r}$ & $\mathbf{N i}$ & $\mathbf{N b}$ & $\mathbf{T i}$ \\
\hline $\mathbf{3 0 8}$ & 0,08 & 2,0 & 1,0 & 0,045 & 0,030 & $19-21$ & $10-12$ & - & - \\
$\mathbf{3 0 9}$ & 0,20 & 2,0 & 1,0 & 0,045 & 0,030 & $22-24$ & $12-15$ & - & - \\
$\mathbf{4 0 9}$ & 0,007 & 0,143 & 0,44 & 0,016 & 0,001 & 11,315 & 0,186 & 0,020 & 0,177 \\
$\mathbf{4 3 9}$ & 0,009 & 0,195 & 0,48 & 0,020 & 0,001 & 17,156 & 0,185 & 0,190 & 0,159 \\
\hline
\end{tabular}

\section{MATERIAIS E MÉTODOS}

Realizou-se, na Empresa Acesita S/A, a soldagem, empregando-se o processo MIG (metal inert gás) de chapas de aços inoxidáveis do tipo AISI 409 e 439, com 3,0mm de espessura, usando como metais de enchimento aços inoxidáveis do tipo AISI 308 e 309, obtendo-se quatro combinações diferentes. A partir destas foram realizados diferentes ensaios e análises. A Tabela 1 apresenta a composição química dos materiais estudados.

Para avaliar as características eletroquímicas dos diferentes sistemas, foram realizados ensaios de polarização potenciodinâmica empregando-se um potenciostato tipo Princeton Applied Research - modelo 237A. As amostras, com $1 \mathrm{~cm}^{2}$ de área, foram lixadas até a granulometria número 600 e desengraxadas. Os ensaios foram realizados em uma célula eletroquímica do tipo plana, com 3 eletrodos, em condições aeradas e na temperatura ambiente. Utilizou-se solução aquosa contendo $3,5 \%$ (peso) $\mathrm{NaCl}$. Após estabilização do potencial de corrosão por 3600s, os sistemas foram polarizados catódica e anodicamente a partir de $250 \mathrm{mV}$ abaixo do potencial de corrosão até aproximadamente $1000 \mathrm{mV}$. A taxa de varredura de potencial eletroquímico foi de $0,166 \mathrm{mV} / \mathrm{s}$.

Para os ensaios de corrosão sob tensão, utilizou-se a técnica de carga constante com corpo-de-prova (CP) do tipo tração-compacto, $\mathrm{C}(\mathrm{T})$, e a de deformação constante do eletrodo (CP em U).

\section{RESULTADOS E DISCUSSÃO}

A Figura $1(a, b)$ apresenta microfratografias dos CPs que foram ensaiados em tração, obtidas no MEV, destacando-se o aspecto dúctil da fratura, através da presença de dimples. Os CPs romperam na região do metal base, evidenciando a boa qualidade da solda.

A partir de vários ensaios de polarização, caracterizaram-se os diferentes sistemas através do levantamento de parâmetros eletroquímicos. A Figura 2 mostra, por exemplo, curvas de pola-

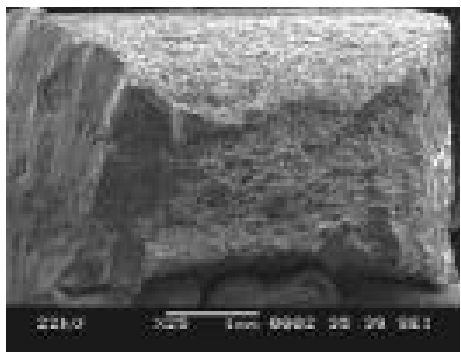

(a)

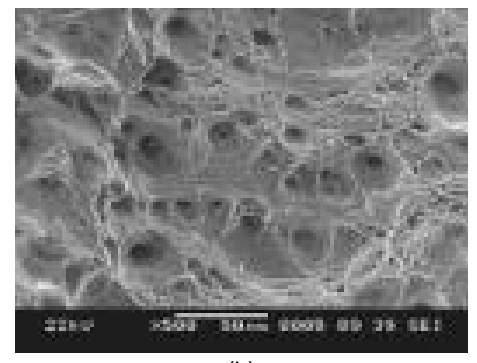

(b)
Figura 1. Microfratografias de CPs de aço AISI 409 soldado com aço AISI 308 ensaiados em tração. Fratura dúctil, presença de dimples; MEV: (a) 25X e (b) 500X. rização potenciodinâmica para os aços inoxidáveis do tipo AISI 409 e 439, respectivamente. Nota-se que o aço inoxidável AISI 439 teve o melhor desempenho, pois possui maior teor de elementos de liga, particularmente, o cromo.

Foram realizados ensaios de deformação constante nas quatro combinações de aços inoxidáveis ferríticos soldados com aços inoxidáveis austeníticos. Estes ensaios foram realizados com soluções aquosas contendo $42 \%$ (peso) de $\mathrm{MgCl}_{2}$ na temperatura de ebulição (aproximadamente $143^{\circ} \mathrm{C}$ ). A Figura 3 apresenta CPs que foram submetidos aos ensaios de TCST. Verificouse que, após aproximadamente 200 horas de ensaio nenhum CP apresentou trincamento.

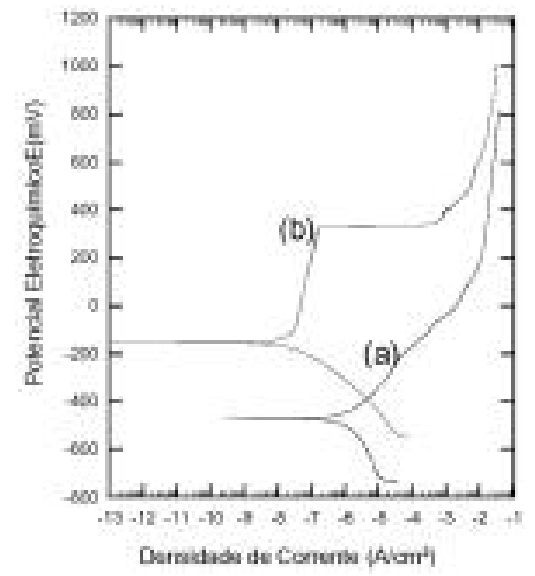

Figura 2. Curvas de polarização potenciodinâmica; $0,166 \mathrm{mV} / \mathrm{s} ; \mathrm{T}=20^{\circ} \mathrm{C}$; sistema: aço inoxidável AISI 409 (a) e AISI 439 (b) em soluções aquosas contendo $3,5 \% \mathrm{NaCl}$.

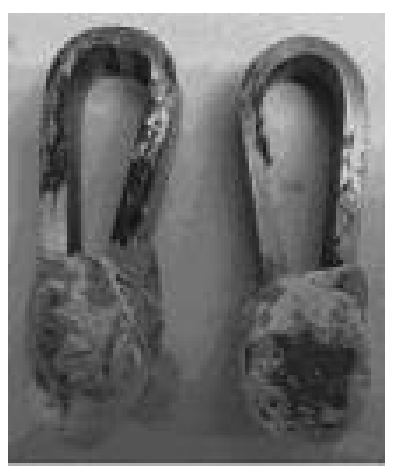

Figura 3. Corpos-de-prova de aço AISI 439 soldado com metal de enchimento de aço AISI 308; em soluções aquosas contendo $42 \% \mathrm{MgCl}_{2}\left(143^{\circ} \mathrm{C}\right)$; não ocorreu trincamento durante aproximadamente 200 horas de ensaio. 
Utilizando-se uma máquina de aplicação de carga constante, foram realizados ensaios de TCST em sistemas constituídos de aços inoxidáveis ferríticos soldados com aços inoxidáveis austeníticos em meios contendo alta concentração de cloretos, por exemplo, $42 \%$ (peso) de $\mathrm{MgCl}_{2}$, e na temperatura de ebulição ( $143^{\circ} \mathrm{C}$ ). Empregou-se 0 ensaio de carga constante por aproximar-se mais das condições reais, onde os efeitos da carga aplicada e o meio são muito importantes. Verificou-se que, com uma carga de $95 \%$ do limite de escoamento dos materiais, todos os CPs tiveram evolução de trinca por corrosão sob tensão. Para esta condição, o tempo médio para a propagação de trincas foi de aproximadamente 48 horas, até o término do ensaio, em todos os materiais. A Figura $4(a, b, c, d)$ mostra alguns CPs trincados por CST.

A Figura $5(a, b)$ mostra fotomicrografias de um CP que sofreu TCST. Os CPs sofreram trincamento. Notam-se trincas principais e secundárias.

A Figura $6(a, b)$ mostra as macrofratografias de CPs tipo tração-compacto, trincados por corrosão sob tensão e que foram rompidos, mecanicamente, em uma máquina de tração na região final de ligamento do mesmo. Nota-se a partir do entalhe a pré-trinca por fadiga, gerada numa máquina servo-hidráulica, MTS de 10t, a região de TCST e finalmente, o arrancamento em tração. As regiões de TCST e de rompimento mecânico por tração variaram em função do nível de carregamento que o material foi solicitado.

A Figura 7 (a,b,c,d) apresenta microfractografias de CPs trincados por CST, obtidas em um microscópio eletrônico de varredura (MEV). Destaca-se o aspecto frágil da fratura, através de facetas de clivagem, em função do fenômeno de TCST. Observa-se, também, que o CP rompido mecanicamente por tração, apresentou fratura completamente frágil onde deveria ser dúctil por se tratar de um aço inoxidável austenítico, o qual normalmente apresenta este tipo de fratura.

Para avaliar se a trinca por CST desenvolvida na região do metal de enchimento de aço inoxidável austenítico, evolui ou não no metal base (aço inoxidável ferrítico), foram confeccionados CPs do tipo tração-compacto, produzidos com aço inoxidável ferrítico, e soldados até praticamente a metade do CP com aço inoxidável austenítico. A Figura 8(a) mostra um dos CPs de aço AISI 409 que foi preenchido com metal de adição do tipo AISI 308 pronto para ser pré-trincado por fadiga e posteriormente ensaiado em TCST. Nota-se na Figura $8(b, c)$ que

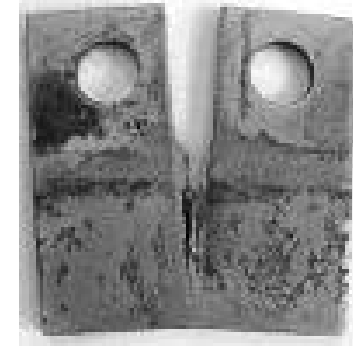

(a)

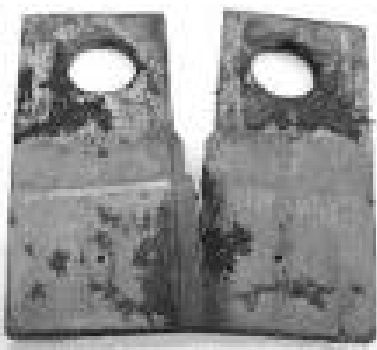

(c)

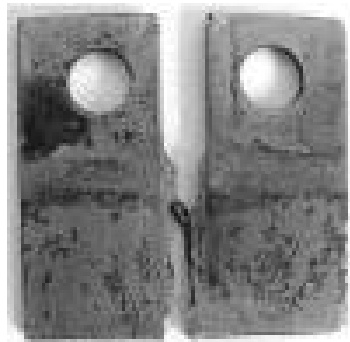

(b)

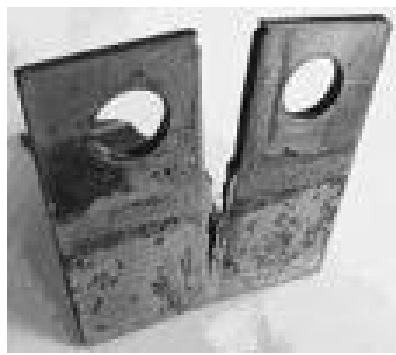

(d)
Figura 4. Corpos-de-prova do tipo tração-compacto, ensaiados em soluções contendo $42 \% \mathrm{MgCl}_{2}\left(143^{\circ} \mathrm{C}\right)$, observa-se a evolução da trinca por CST; $\mathrm{K}_{\mathrm{I}}=68 \mathrm{MPa} \sqrt{m}$; (a) aço AISI 409 soldado com aço AISI 309; (b) AISI 409/AISI 308 (ruptura completa); (c) AISI 439/AISI 309; AISI 439/AISI 308.

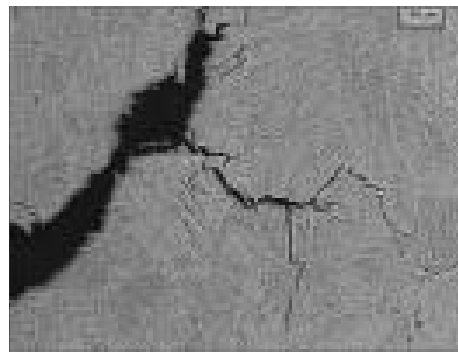

(a)

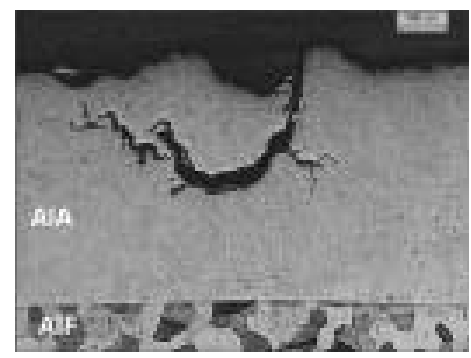

(b)
Figura 5. Fotomicrografias de um CP (aço AISI 409) trincado por CST na região do cordão de solda (metal de adição AISI 308); (a) trinca principal com ramificações; 100X; (b) trinca principal na região do aço inoxidável austenítico (zona fundida); 25X. AIA - aço inoxidável austenítico; AIF - aço inoxidável ferrítico; Reativo: Vilela.

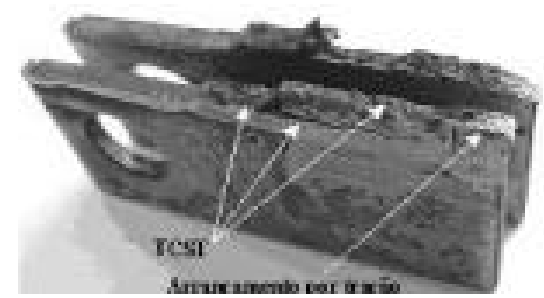

(a)

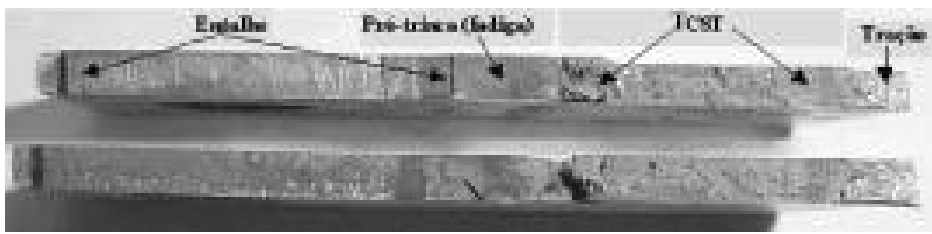

(b)

Figura 6. Macrofotografias de CPs trincados por CST; carga constante; (a) e (b) sistema: aço AISI 409/AISI 308 em soluções aquosas contendo $42 \% \mathrm{MgCl}_{2}\left(143^{\circ} \mathrm{C}\right)$. Notam-se os aspectos frágeis da fratura por TCST e por tração. 


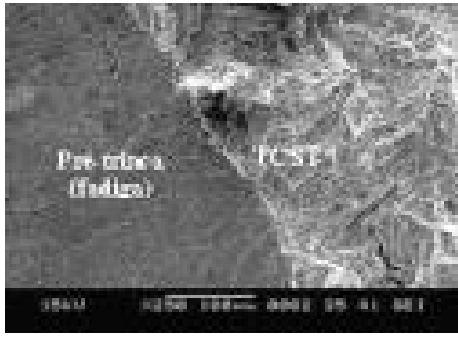

(a)

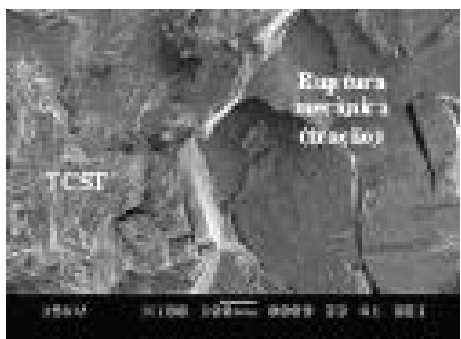

(c)

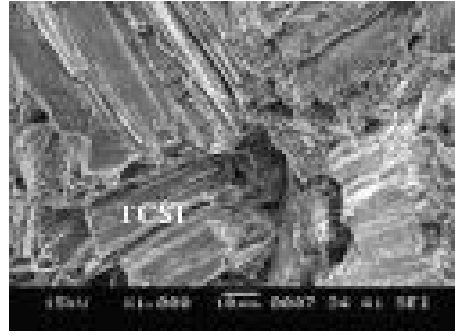

(b)

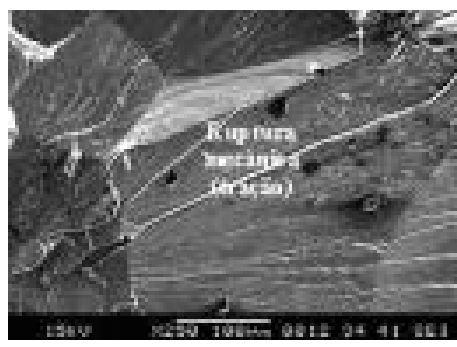

(d)
Figura 7. Fotomicrografias de CPs trincados por CST; carga constante; sistema aço AISI 409/AISI 308 em soluções aquosas com $42 \% \mathrm{MgCl}_{2}$ $\left(143^{\circ} \mathrm{C}\right)$; (a) pré-trinca por fadiga e região de TCST, 250X; (b) TCST, 1000X; (c) TCST e tração, 100X; (d) tração, 250X. Nota-se fratura frágil na região de TCST e no rompimento por tração (facetas de clivagem); MEV.

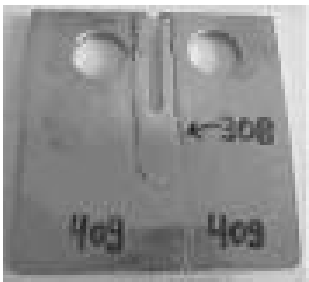

(a)

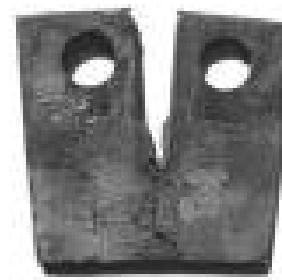

(b)

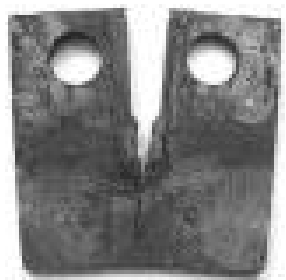

(b)
Figura 8. Corpos-de-prova tração-compacto; (a) metal base (incluindo a zona de ligação) de aço AISI 409 e metal de enchimento de aço AISI 308; (b) e (c) CPs correspondentes à Figura 8(a) ensaiados sob carga constante; soluções aquosas contendo $42 \% \mathrm{MgCl}_{2}\left(143^{\circ} \mathrm{C}\right)$.

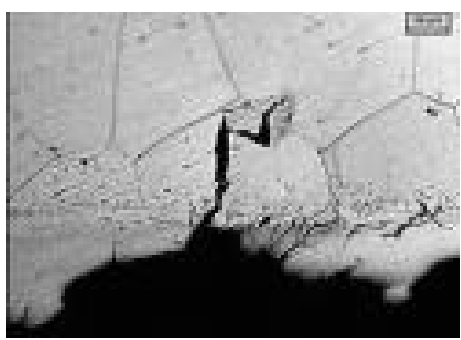

(a)

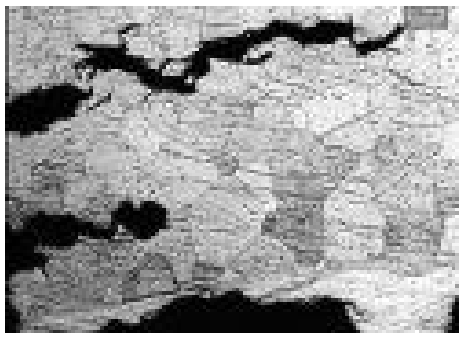

(c)

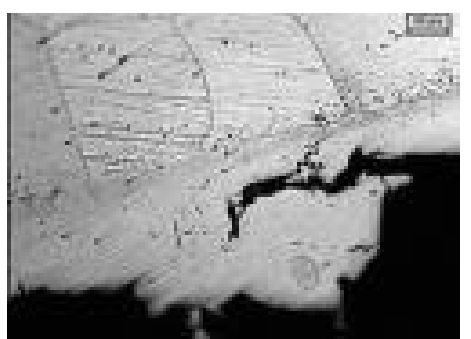

(b)

(d)

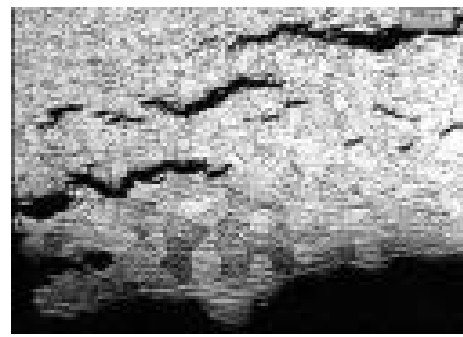

Figura 9. Fotomicrografias de CPs trincados por CST correspondentes à Figura 8; evolução de trincas na ZF (aço inoxidável austenítico): (a) e (b); para a ZTA e MB (aço inoxidável ferrítico): (c) e (d). Aumentos: 200X (a), (b); $50 X(c) ; 25 X(d)$. Ataque: Vilela. o trincamento ocorreu na região austenítica (ZF) e se propagou para a parte ferrítica (zona de ligação do $\mathrm{CP}$ ). No entanto, alguns $\mathrm{CPS}$ não sofreram TCST em função do baixo nível de carregamento aplicado nos ensaios, mas as regiões mais tencionadas sofreram maior ataque corrosivo (zona de ligação do CP).

A Figura $9(a, b, c, d)$ apresenta as trincas desenvolvidas por CST na região da ZF (aço inoxidável austenítico) e evolução na ZTA e MB (aço inoxidável ferrítico).

Vieira et al.,(6) estudaram o comportamento em corrosão sob tensão de aços inoxidáveis ferríticos soldados com metal de enchimento contendo ligas inoxidáveis austeníticas. Pinto(7) também analisou a suscetibilidade ao trincamento por CST de uma liga do tipo AISI 444 soldada com metal de adição de aço inoxidável austenítico, do tipo AISI 316LSi. Os ensaios foram realizados na temperatura ambiente, com emprego de solução contendo $1 \mathrm{M} \mathrm{HCl}(\mathrm{pH} \cong$ 0,0 ), e em meios contendo $42 \% \mathrm{MgCl}_{2}$, na temperatura de ebulição $\left(143^{\circ} \mathrm{C}\right)$. Os resultados obtidos por ele foram similares aos encontrados neste trabalho.

Pinto(7) também observou que para os dois meios analisados 0 material sofreu trincamento por CST, onde o fenômeno ocorreu a partir da pré-trinca por fadiga, na zona austenítica, e prosseguiu para a zona ferrítica.

Outro aspecto importante notado é que, em função do emprego de um metal de adição com aço inoxidável com certo teor de silício (com propósito de aumentar a fluidez na soldagem), a ruptura final, por arrancamento em tração, também apresentou comportamento frágil semelhante ao TCST.

\section{CONCLUSÕES}

- O aço AISI 439 apresentou melhor comportamento em relação à corrosão quando comparado com o aço AISI 409, através de ensaios de polarização potenciodinâmica em uma solução de $\mathrm{NaCl} 3,5 \%$;

- A junta soldada de aço AISI 409, com metal de enchimento de aço AISI 308, sofreu ruptura nos ensaios de dobramento;

- Aços AISI 409 e 439 soldados com metais de adição de aços AISI 308 e 309 em meios com $42 \% \quad \mathrm{MgCl}_{2} \quad\left(143^{\circ} \mathrm{C}\right)$ ensaiados sob deformação constante no eletrodo, não apresentaram trincamento por CST;

- Os ensaios de carga constante no eletrodo mostraram que os aços inoxidáveis ferríticos soldados com metal de enchimento de aços 
inoxidáveis austeníticos trincaram por corrosão sob tensão, em soluções aquosas com $42 \% \mathrm{MgCl}_{2}$ em ebulição.

- O tempo para o trincamento, sob carga constante, foi relativamente curto em níveis de cargas próximos ao limite de escoamento do material. Para estes casos, notou-se, também, o efeito da ramificação de trincas.

- As trincas por CST, nos ensaios de carga constante, propagaram-se nas regiões do aço austenítico e do aço ferrítico.
- Análises microfratográficas mostraram que o tipo de fratura foi frágil, com o desenvolvimento de facetas de clivagem. Isto ocorreu na região de TCST e também na zona de arrancamento final por tração no CP.

\section{Agradecimentos}

Os autores agradecem a Companhia ACESITA e ao Programa de Pós-Graduação em Engenharia de Materiais da REDEMAT.

\section{REFERÊNCIAS}

1 JONES, R.H. Stress-corrosion cracking: materials performance and evaluation, Ohio: ASM International, 1992.448 p.

2 CHAWLA, S.L.; GUPTA, R.K. Materials selection for corrosion control. Materials Park, Ohio: ASM International, 1995. $508 p$.

3 JONES, D.A. Principles and prevetion of corrosion. New York: Macmillan, 1992. 568p.

4 CÂNDIDO, L. C. Corrosão sob tensão de aços inoxidáveis duplex, em soluções aquosas contendo cloretos, na temperatura de ebulição, através de diferentes técnicas experimentais. 1996. 203p. Tese (Doutorado em Ciência e Engenharia de Materiais) - Programa de Pós-Graduação em Engenharia Metalúrgica e de Minas da Universidade Federal de Minas Gerais. Belo Horizonte, 1996.

5 GODEFROID, L.B. Fundamentos de mecânica de fratura. Ouro Preto: UFOP, 1995.

6 VIEIRA, D.H.; PINTO, D.F.; DE CARVALHO, J.A.N.; BÁLSAMO, P.S.S.; GODEFROID, L.B.; CÂNDIDO, L.C. Estudo do fenômeno de corrosão em juntas soldadas de aços inoxidáveis. In: CONGRESSO ANUAL DA ABM, 60., 2005, Belo Horizonte. Anais... São Paulo: ABM, 2005. 1CD. p. 555-565

7 PINTO, D.F. Comportamento em corrosão sob tensão de um aço inoxidável ferrítico AISI 444 soldado com aço inoxidável austenítico AISI 316LSi, em meios contendo cloretos. 2006. 107p. Dissertação (Mestrado em Engenharia de Materiais) - Programa de Pós-Graduação em Engenharia de Materiais Universidade Federal de Ouro Preto. Ouro Preto, 2006.

Recebido em: 20/02/2006

Aceito em: 14/12/2006

Proveniente de: CONGRESSO ANUAL DAABM, 60., 2005, Belo Horizonte. São Paulo: ABM, 2005. 